\author{
MATYLDA AMAT OBRYK \\ Northeast Normal University, Changchun \\ Heinrich Heine University, DüsSeldorf
}

\title{
PASSING ON WISDOM PLATO ON WISDOM AND MEMORY ${ }^{1}$
}

\begin{abstract}
By means of an analysis of the tension between orality and literacy the following paper tries to discover how Plato understood the task of transmitting wisdom. Considering his vehement critique both of poetry and of writing, a sharper understanding of the nature of Platonic wisdom came about. Wisdom seems to be beyond all appearances and can be achieved only through dialogue within meaningful relationships.
\end{abstract}

KEY WORDS: Orality, literacy, Platonic wisdom, memory

The research for this article has been mainly conducted at the library of the Hardt Foundation in Geneva, Switzerland in February 2015. The memories of scholarship and the wonderful atmosphere at the Foundation are unforgettable. Here I would like to officially thank the Hardt Foundation for the immense support I enjoyed during the stay.

The article is part of a larger project on Transmission of Values based at the Institute for the History of Ancient Civilizations at the Northeast Normal University. The volume will be a collection of several articles by Chinese scholars and will be published in Chinese translation. Here I would like to thank Prof. Zhang Qiang for the permission to publish it in the English version. 


\section{INTRODUCTION}

A central issue for every culture is how to pass on knowledge and wisdom to the next generation. Besides the question of deciding what is valuable enough to be transmitted, the channels of transmission vary considerably depending on the circumstances, time, and available media. The aim of this paper is to analyze Plato's thoughts on the transmission of wisdom during a major cultural paradigm shift: the transition from an oral to a literate culture. The focus of this paper will be on the Phaedrus as it most clearly pertains to the question of orality versus literacy.

In an oral culture everything that is considered important enough to be passed down to the next generation needs to be encoded in poetry: in rhythmical speech that provides a relatively stable frame and enhances the chances of memorization. For many centuries the frame was imagined to be stiff and rigid - unchangeable. The research of Milman Parry brought a deeper understanding of the nature of that frame. Parry convincingly showed that poetry of the oral tradition is not a dead form, which was supposed to be memorized word by word. The poets were not automata reciting hundreds of verses in an unchanging manner. The content was entrusted to formulas, which could be combined according to the needs of the poet - they are to be imagined as bricks out of which new buildings can be built. ${ }^{2}$

Additionally, almost everything that was supposed to be transmitted had to be dressed in the clothing of stories. Poetry was therefore to a great extent a storytelling enterprise. Stories, themselves built on formulas, were the scaffold on which knowledge was arranged. In this way, poetry became a treasury of knowledge, a kind of encyclopaedia of the people. ${ }^{3}$ This encyclopaedia, though, was of a different nature from the one we are acquainted with. Nowadays an encyclopaedia incorporates all the knowledge of a given time, capturing and freezing it. The ancient encyclopaedia was - following Parry - a living one, as the medium for it

Parry 1971: 172-175.

Havelock (1963: 61-86) devoted a whole chapter to the question of epic, especially Homeric poetry, as an encyclopaedia for the Greeks. 
was not a dead book but a living human being. To what extent this aspect of the life of poetry is true will be investigated in the following pages. ${ }^{4}$

Thanks to Parry's research we know that this treasury of poetry was in constant flux, changing according to the poet, audience, or time. This fluctuating and pulsing material necessarily influenced the way people thought about and perceived reality to a great extent. ${ }^{5}$ Knowledge in an oral culture is a living and vibrant mass that is being constantly reinterpreted and changed. This dynamic character of knowledge underlying the whole of Greek culture may have influenced its lack of dogmatism that is so characteristic of it and so inherent in it. ${ }^{6}$ The many versions of myths existing in parallel on equal rights throughout time and space may go back to this very feature of oral culture. What is important and seen to be valuable enough to be transmitted to the next generation is not so much the exact content of the stories or their exact plot and sequence, but the values and emotions transmitted by means of the content. ${ }^{7}$ Oral culture can therefore be seen as a breeding place of all dynamic intellectual processes. Plato takes notice of that fact, but to him even the poetic state of mind is not sufficiently dynamic to guarantee the achievement of his - philosophical - goal. His approach to both literacy and poetry is going to be the central point of this article. He puts both of the available media through which knowledge is transmitted (poetry and writing) in the dock. In the following discussion we will search for the answer to the

4 The living force that is so very important to Plato lies in a different realm than what we are here talking about.

5 Havelock (1963: 134-144) called it the "Homeric Mind" and devoted a whole chapter of his book to it.

6 As rigidity and stability of content cannot possibly be connected with oral culture, it is only within the framework of literate culture that dogmatism - meaning persistence on one version of a story, myth or history - could be enforced. Cf. as well Cornford (1957: 2): "Now, it is true that the Greek philosophers were exceptionally untrammelled by dogmatic prejudice and priestly persecution; they were fortunate enough to be born into a state of society which was satisfied, in the main, with an outward conformity, and allowed reason to pursue her inward task of seeking the truth which makes us free."

For instance, the Iliad makes an attempt to depict intense emotions and the tragic fate of Achilles before the backdrop of a massive war. The tragedies themselves used different plots of the myths in order to lead the audience - in the understanding of Aris-

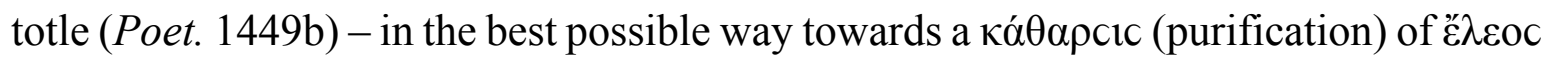

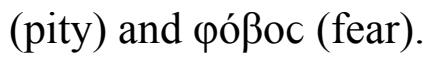


question of what unites both of them and what is the reason for Plato to reject them.

\section{NEW MAN}

In his dialogues - especially in the Republic - Plato designed a comprehensive system. He talked about a new kind of wisdom: the dialectical copí $\alpha$ that is to be understood as self-knowledge ${ }^{8}$ and a new and somewhat revolutionary approach to its transmission. The investigation of the way of transmitting copí $\alpha$ will lead us to some discoveries about the nature of wisdom itself.

There are two basic ways of passing down knowledge. In the first one it goes through the ear, in the other through the eye. One is therefore oral, the other is based on writing. In our world of dualism and binary logic it may appear surprising that Plato, seeing the dangers of one of them, does not automatically embrace the other. Apparently, he is able to see the difficulties and danger both may bring about. He evaluates the two channels of transmission from yet another, apparently philosophical, standpoint. The reasons for his charges become revealed in the next pages.

\subsection{Plato's criticism of poetry}

As already mentioned, poetry in an oral culture is the treasury of all knowledge that can be known. This kind of knowledge is inherently and compulsorily dynamic. The major bulk of the critique that befalls poetry from Plato's side is centred firstly around the content of poetry and secondly around the means of its preservation and communication. ${ }^{9}$

The critique regarding the content is to the modern eye somewhat surprising, as we are not accustomed any more to take art at face value but tend to appreciate even the slightest aesthetical aspect of anything

\footnotetext{
$8 \quad$ Griswold 1981.

9 On that topic a vast amount of literature has been already produced. A recent article by Griswold on this topic with a list of up-to-date bibliography may be found in the electronic version of the Stanford Encyclopaedia of Philosophy: Griswold 2014: http:// plato.stanford.edu/archives/fall2014/entries/plato-rhetoric/. I will mention the topic only briefly and stress only the points that are relevant for the current discussion.
} 
that may carry the name of art. In regard to the content Plato criticizes the all too anthropomorphic depiction of gods or the immoral behaviour of heroes and so is not willing to include this kind of story, which he calls "false", in the school curriculum in his ideal state (mainly Resp. II). ${ }^{10}$

On the other hand poetry, being entrusted with the conservation of a particular kind of knowledge, was compelled to perpetuate a certain mindset (cf. above n. 3). And for Plato it was unacceptable, for this kind of poetic mind was not capable of any reflection. ${ }^{11}$ The mindset Plato is criticizing and which he regards as detrimental to his goal is, according to Havelock, the image-thinker. ${ }^{12}$ This mindset was a product of $\mu$ í $\mu$ cıc (imitation) that consisted of images and pictures that were a kind of sce-

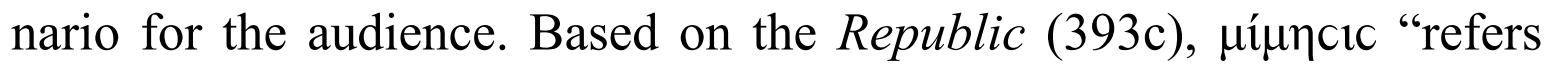
to a rhythmically induced experience and habit of identifying with, and making one's own, the words and actions of another as one hears poetry being emotively narrated and chanted." 13

To understand this point more fully it could be helpful to turn to the question of what kind of knowledge was being transmitted through mimetic poetry. As we have noted above, the knowledge transmitted through oral poetry is not strictly fact-oriented. Poetry served as a treasury of examples and patterns of behaviour. It delivered just plain scripts of actions that were supposed to be performed in certain situations without engaging either the intellect or the capacity for reflection. The most striking example is the script-like description of the hospitality of the Phaeaceans in the Odyssey (Books 6 and 7). It served obviously as a catalogue of gestures and rituals, and as a manual on receiving a $\xi \dot{\varepsilon} v o c .{ }^{14}$

10 Interestingly the dichotomy between true and false stories is not only found in Plato. The Muses of Hesiod claim to be able to provide both kinds of stories for the willing poet and listener. What is even more striking is the fact that they pride themselves on

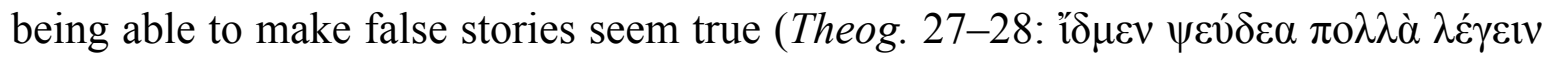

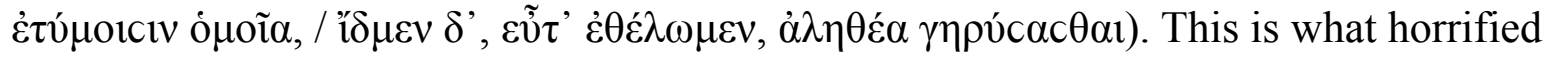
Plato the most: not being able anymore to discern between falsity and truth.

11 "Such enormous powers of poetic memorisation could be purchased only at the cost of total loss of objectivity. Plato's target (scil. of criticism) was indeed an educational procedure and a whole way of life" (Havelock 1963: 45).

12 Havelock 1963: 276.

13 Robb 1994: 214.

14 Robb 1994: 28-31 and 219. Taking into account the catalogue of ships from Iliad 2 we see that factual information was at times also entrusted to the hands of poets. 
Plato, who was aiming at bringing forth a new type of man, could not possibly agree with a $\pi \alpha 1 \delta \varepsilon i ́ \alpha$ that created men suited to the old societal structure. He sees in it an impediment to developing independent thinking and ultimately the real kind of memory, the $\alpha v \alpha$ av the poet-performer and listener.

In addition, in order to be kept alive, poetry had to evoke strong emotions. Poetry was compelled to enthrall the audience. Otherwise it would have been ineffective as a medium for transmitting knowledge. ${ }^{15}$ The complete diving into a story ensured its preservation but left no room for any reflection and questioning of either the content or the form. For Plato this was the most unacceptable feature of poetry as it addressed the lowest stratum of the soul, the $\dot{\varepsilon} \pi \imath v u \eta \eta \tau \kappa o ́ v .{ }^{16}$ In that way poetry is the antipodes of $\varphi \rho$ óvๆctc, which is the goal of the philosopher (Resp. 603a11-603b1).

The advent of philosophy and then subsequently of the alphabet seemed to have the potential to bring a change of paradigm. But how Plato assessed this new medium is going to be the topic of the next passage.

\subsection{Critique of Writing}

Havelock ${ }^{17}$ claims that for Plato philosophy meant something comparable to intellectualism, and consequently the capability of abstract thinking. In any case it meant a major shift of paradigm, and was born in pain and entered the world in a somewhat crude way. At first philosophers took advantage of the revolutionary technology of writing but did so still largely orally. They wrote texts meant to be recited and heard rather than read. ${ }^{18}$ Parmenides and Empedocles both created a genre which revolutionized the content but which relied strongly on the epic tradition

\footnotetext{
15 Cf. Frentz (2006: 247): “Any careless moment of self-reflection, any lapse in concentration, anything that might break the spell of the muse could result in lost knowledge."

16 Cf. Resp. 435e-439d; Havelock 1963: 4 and 9.

17 Havelock 1963: 284.

18 Havelock 1963: 288.
} 
regarding the form. ${ }^{19}$ Their followers slowly realized that poetry is not suitable any more for this kind of enterprise. ${ }^{20}$

In order to understand Plato's train of thought on the transmission of wisdom more clearly we have to turn now to his consideration of the usefulness of letters as a new technology for this purpose. On the one hand, he mentions letters as obvious first steps in the course of knowledge acquisition (Theaet. 206a). ${ }^{21}$ On the other, he obviously criticizes writing. Previously we have seen that Plato - while embarking on the quest for the best education for his ideal state - criticizes poetry as a representative of oral culture on the whole. Instead of embracing then the apparent opposite of the poetic state of mind, i.e. writing, he makes a similar accusation against it. Let us then have a closer look at Plato's views on writing.

It is striking that the Phaedrus itself starts with a description of Phaedrus carrying a book containing Lysias' speech on love under his arm with the intention of learning it by heart. He is obviously charmed by it. In the course of the dialogue it will be proven by Socrates that the speech has some flaws and should not be accepted as truth. But Phaedrus is apparently not concerned with the value of this speech so much. He wants to memorize it in order to be able to reproduce it at a given time, probably in order to impress the audience. And in that way Plato shows that this written speech lying before Phaedrus and ready to be memorized deprives him of any faculty of dialectic. He literally surrenders himself to those rolls of papyrus. ${ }^{22}$

In that notion we begin to sense that the resemblance between poetry and the written word in terms of the ability to enthrall the audience is very close. Both produce only appearances (of wisdom, as Thamus is going to stress). They both enchant their prey putting a veil on their eyes and ears. To be able to see the reality as it is the veil of whatever

\footnotetext{
19 Cf. Wöhrle 1993.

20 Interestingly, the central issue of the Parmenidean poem is the reflection upon $\delta$ ó $\xi \alpha$ and $\dot{\alpha} \lambda \hat{\eta} \theta \varepsilon 1 \alpha$, which both appear as main points in Plato's critique of poetry and writing. However, the connection between Parmenidean and Platonic interpretation of those terms cannot possibly be dealt with at present.

21 From this we can understand that Plato is already strongly embedded in a literate world wherein the imagery of letters was familiar to all to whom the dialogue might have been addressed.
}

22 Cf. Frentz 1996: 247. 
provenance it has must be removed. Therefore writing is as much detrimental to true insight into reality as was poetry.

Let us recall the scene. The critique of writing comes dressed as one of Plato's most famous myths. Socrates employs Thamus ${ }^{23}$ and Theuth, two divine Egyptian personalities, in order to convey his message. In the course of an ardent discussion of correct speech Socrates begins telling a story that he heard from the ancients (Phaedr. 274c). The ancients must be the Egyptians. ${ }^{24}$ Whenever Plato wants to make an important point, he turns to Egypt as the source of ultimate authority. ${ }^{25}$ In the case of writing it is no different. Theuth, the god of writing and science, presents his discoveries and inventions to the king of gods, Thamus. Having shown him a series of inventions, including dice, draught, numbers, and arith-

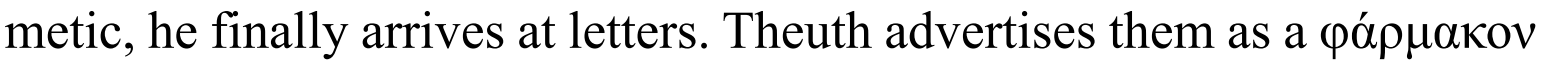
(medicine or poison, elixir or nectar) of wisdom as it is understood to be an aid to memory (Phaedr. 274e). Thamus vehemently stresses the fact that as father-inventor he is - out of love for his invention - somewhat partial to it and cannot evaluate it correctly.

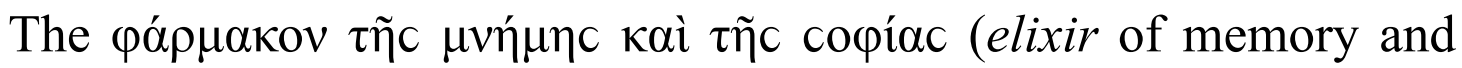
wisdom) should be understood as a hendiadyoin, as for the Greeks memory and wisdom are inseparable. There is no wisdom without memory and a certain kind of memory, as we are going to find out just in a moment, is in fact the only true wisdom.

23 The identity of Thamus is from the Egyptological point of view slightly difficult to define. Plato mentions that Thamus is the king of all Egypt, based in Egyptian Thebes and was called Ammon by the Egyptians themselves (Phaedr. 274d). If we assume that Thamus is therefore an alternative name for the Egyptian god Ammon-Ra it brings forth certain interpretational nuances, which are going to be brought to light in the following. On Thamus and the identification of this name within the context of Egyptian gods cf. Thissen 2002: 54-61.

24 The Egyptians were the impersonation of antiquity for the Greeks (cf. Heinrichs 2003: 225, esp. n. 55 and 56).

25 Interestingly, Phaedrus remarks in 275a that Socrates is able to invent stories from whatever country he likes. The answer of Socrates to this accusation is central for our understanding of the Socratic approach to wisdom: he remarks that in older times people accepted the words of the oak or trees as long as they were true, nowadays everyone relies on analysing the speaker's background when estimating the value of their speech. An interesting question at this point, which, however, exceeds the limits of this paper, would be by what other criteria one is supposed to evaluate the truthfulness of a story. 
The first point of criticism that is crucial and central to our discussion is the accusation that only an appearance of wisdom rather than wisdom

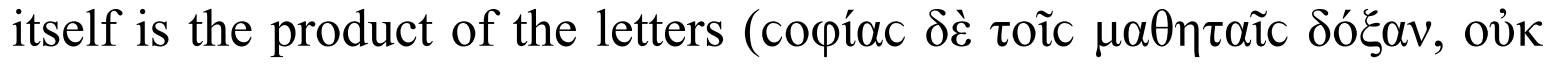

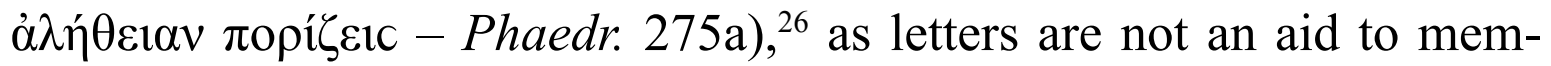

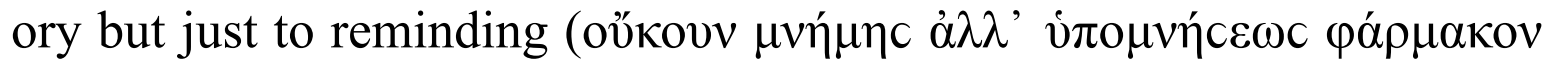
$\eta \tilde{v} \rho \varepsilon c-P h a e d r .275 a) .{ }^{27}$ Theuth wanted to see letters as a device for improving memory, instead, as Thamus pointed out, the letters will produce forgetfulness as people are not going to exercise their memory and will rely on those external devices (ibidem). According to those central sen-

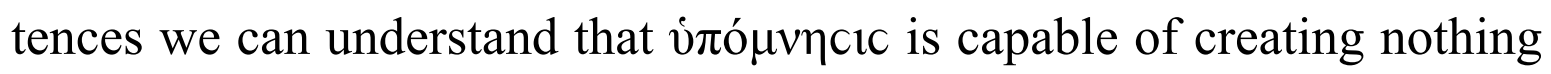
but an appearance ( $\delta$ ó $\xi \alpha$ ) of wisdom. And wisdom (copí $\alpha$ ) is the product solely of $\mu \nu \eta \dot{\mu \eta}$.

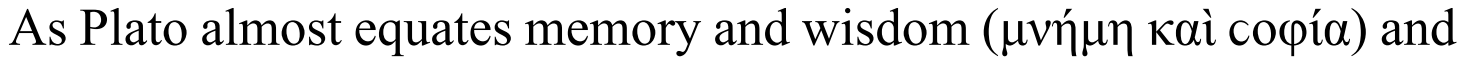
makes the detrimental effect that letters exert on memory the most important charge against writing, we should look carefully into the question of the status of memory.

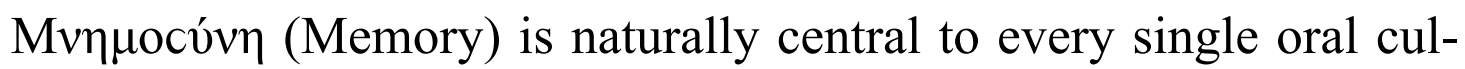
ture. The entire heritage and identity of a culture relies on memory. ${ }^{28} \mathrm{Her}$ special place in Greece is even marked by her position among the gods of myth: she is among the first Titans, children of Ouranos and Gaia (Hes. Theog. 135). She is - by Zeus - the mother of the nine Muses. It is remarkable to note that she stands almost at the beginning of the whole Olympic genealogy. There is no world, no culture at all without her. There is no fruit of the Muses without their mother, Memory. With-

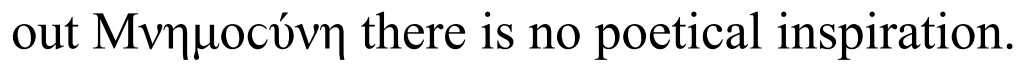

Interestingly she is not only vital within the traditional poetical culture. In the oral tradition she preserves the total state of mind encompassing just about every aspect of human life. ${ }^{29}$

26 "And you offer your pupils the appearance of wisdom, not true wisdom" (here and hereafter transl. Fowler).

27 "You have invented an elixir not of memory but of reminding".

28 Havelock points out that poetry relying on memory was not just an aesthetical enterprise or a form of entertainment and it ,was not literature but a political and social necessity. It was not an art form, nor a creation of the private imagination, but an encyclopaedia maintained by co-operative effort on the part of the best Greek polities" (1963: 125).

29 Havelock 1963: 134. 
On the other hand, for the sprouting new movement of philosophical inquiry and investigation, memory again plays a central role. In the first philosophical brotherhood gathered around Pythagoras she can be spotted most clearly. ${ }^{30}$ The exercise of memory was one of the central practices of the disciples of Pythagoras who were encouraged to pursue the quest for divine virtue in that way. The Golden Verses (Carmina Aurea) preserved under the name of Pythagoras testify a very stringent exercise every member of the society had to undergo:

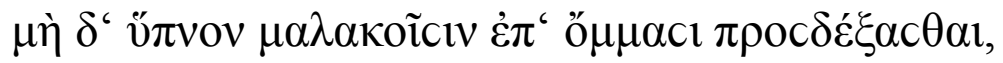

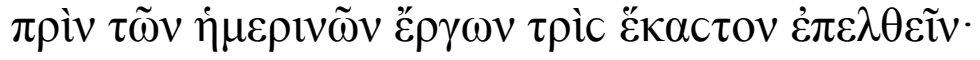

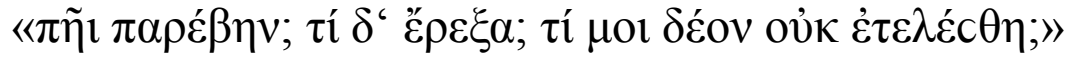

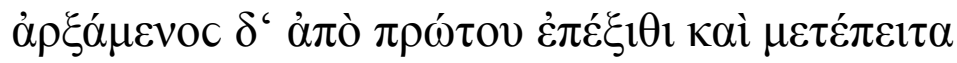

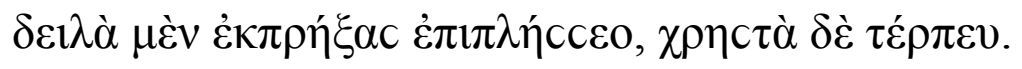

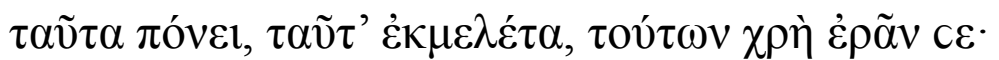

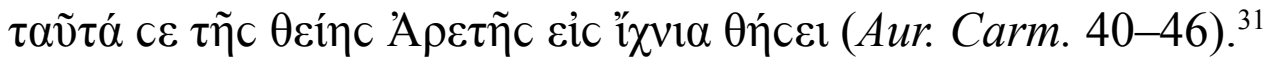

Vernant remarks in this connection that the Greeks seem almost obsessed by memory as they associated it with life and immortality. ${ }^{32}$ Oblivion, on the other hand, means death to the Greeks. ${ }^{33}$ And this can be seen from a number of different perspectives.

$30 \quad$ Cf. Vernant 2006: 127.

31 "Never allow sleep to close your eyelids, after you went to bed / Until you have examined all your actions of the day by your reason./ In what have I done wrong? What have I done? What have I omitted that I ought to have done? / If in this examination you find that you have done wrong, reprove yourself severely for it; / And if you have done any good, rejoice. / Practise thoroughly all these things; meditate on them well; you ought to love them with all your heart. / It is those that will put you in the way of divine virtue" (transl. Firth).

32 Vernant 2006: 122.

33 To state the obvious: $\lambda \dot{\eta} \theta \eta$ causes death exactly as her opposite, $\dot{\alpha} \lambda \dot{\eta} \theta \varepsilon 1 \alpha$, causes immortality. And $\dot{\alpha} \lambda \dot{\eta} \theta \varepsilon i \alpha$ can be achieved only through the means of $\mu \nu \eta \mu$ ocv́vๆ. The Orphic-Bacchic golden tablets provide the imagery. They describe the path the dead person is supposed to choose and the gestures he or she is supposed to make. First of all he must avoid the river of Forgetfulness (the $\Lambda \eta \theta \eta$ ) and search for the spring of

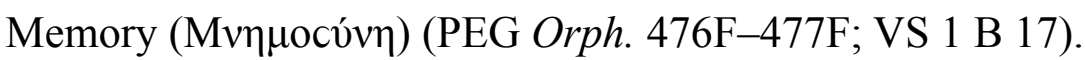

The $\Lambda \eta \theta \eta$ is even able to hold back someone in Hades as in this grave inscrip-

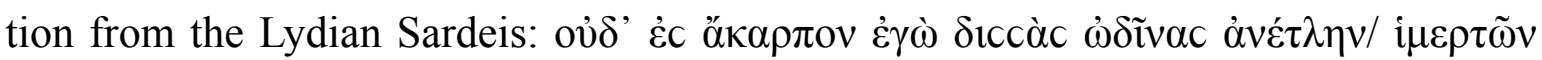

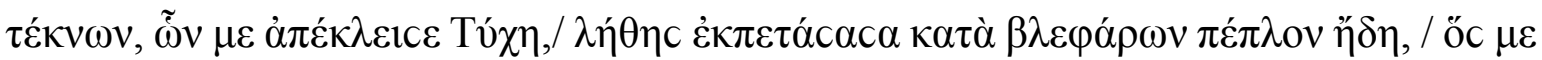

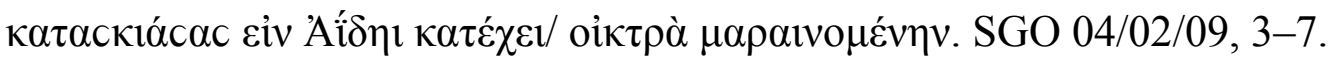


Diotima explains Socrates that all human activities pertain ultimately to one specific and inherent longing (Symp. 208c-208e). The aim and goal of every action and every life is to find a way to achieve immortality. Most people attain it by producing offspring, others try to perform glorious deeds and in that way to impress their own names upon the memory of the generations to come. In both situations everything ultimately centres around the question: Who is going to utter my name, recall my life and deeds after my death? Ordinary people hope that their offspring will perform the ritual acts of memory. Men of action seek a wider circle of people who will remember them maybe even longer than for three generations. And then others turn to philosophy and achieve real immortality through the care of the soul, as Diotima points out.

The search and longing for immortality ensured through memory is also vividly seen in inscriptions. Only through memory are we able to achieve immortality. The preservation of memory is one of the simplest ways of achieving a life after death. All funerary inscriptions were supposed to preserve the name and ensure that the memory of the deceased would be preserved..$^{34}$ There is no other need for installing a stele or chiselling an inscription than to preserve the memory of the deceased. Not only are memory in earthly life and the prolongation of earthly existence mentioned, but furthermore the notion of memory in the netherworld.

The $\Lambda \eta \forall \eta$, the river of Forgetfulness in the Hades, is the de facto cause of death and of never returning to the world of life. Plato describes the river $\Lambda \eta \eta \eta$ in the famous passage about the Pamphylian Er (Resp. $\mathrm{X}$ 614-621). To quench the burning thirst in the Netherworld one has to avoid excessive drinking from the $\Lambda \eta \eta \eta$ as this would cause a loss of identity (Resp. X 621a-621c). Only remembering who one was on earth and what one saw in the netherworld increases the chances of achieving a better life in the next turn and then ultimately of liberation from the circle of birth and death. The $\Lambda \eta \dot{\theta} \eta$ is the reason why those who drank from it remain trapped within that circle, which Plato recognized as being detrimental to human development. He saw the goal of human life in liberation from the necessity of being born again. And that was to be achieved through the means of memory, which is to be understood as almost identical with consciousness or the awareness of self-identity. The

34 Cf. Obryk 2012: 78-84. 
proper awareness of one's own position in the world would ensure the right choice in the Hades and then ultimately pave the way for the next life and finally the exodus from earthly existence altogether.

As we have seen in the critique of letters, the most important accusation was grounded in the presupposition that letters increase the powers of forgetfulness, $\Lambda \eta \theta \eta$, and therefore simultaneously the domains of death, non-truth and non-knowledge as Derrida points out. ${ }^{35}$ Subsequently, not only to be forgotten but also to forget is to die. Socrates himself brings the dichotomy of life and death within his discourse on writing. He speaks in terms of lifeless and living speech. What can really lead to the goal of

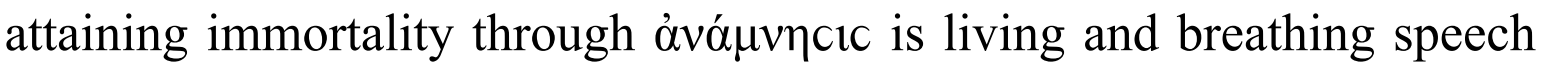

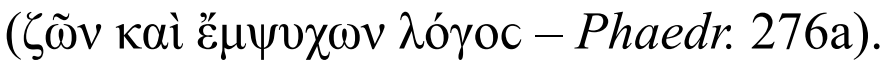

And this makes the Platonic myth in the Phaedrus even more striking: according to Egyptian mythology the god Theuth presides not only over letters and arithmetic, but is at the same time responsible for the domain of death. The master of writing and calculation is at the same time the master of death. Letters numb and drug memory - the only means for achieving life and immortality - and therefore increase the powers of death; therefore, they naturally belong to Theuth's prerogatives. On the other hand, Thamus-Ammon, the god of the sun, Theuth's counterpart, and - following his fusion with $\mathrm{Ra}$ - the creator god, strongly advocates living words and along with them living memory beyond any external aids. ${ }^{36}$

The whole of Greek culture is therefore a culture of memory. And that can be seen on different levels. Memory is omnipresent in all the features of the culture: from the poetical stage of an oral culture, through the first philosophical steps to the full-fledged assessment of its value in Plato. The highest level is the philosophical memory that is called by Plato ơvó $\mu v \eta c ı c$; it pertains to achieving a spiritual kind of immortality going hand in hand with what is called self-knowledge.

To sum up Plato's approaches to memory: he distinguishes between

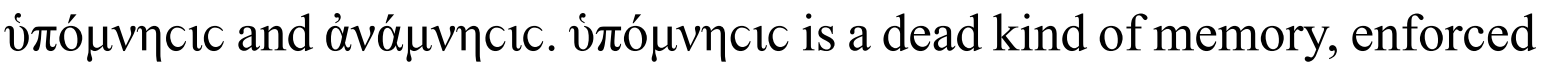

\footnotetext{
35 Derrida 1981: 105.

36 This dichotomy of life and death works only within Plato's imagery and in his interpretation of the Egyptian gods. For an Egyptologist this might appear not fully agreeable as this kind of dualism is not common in Egypt. Plato transforms and uses the Egyptian picture according to his particular needs.
} 
both by poetry and by writing. ${ }^{37}$ He realises that both poetry and writing, despite being poles apart from one point of view (as they pertain to different cultures: oral and literary one), nevertheless pursue their quest in a similar way. Poetry uses formulaic language and ultimately emotions as crutches for memory. The letters are a crutch for memory per definitionem.

The second charge against writing revolves around the issue of exchange and real dialogue within a relationship that is a condicio sine qua non for the transmission of knowledge. Socrates uses an analogy between writing and painting: as paintings seem to be alive at first but when asked about anything cannot reply, so very similarly letters seem only to be intelligent, talking eloquently about many issues but on being asked they maintain a solemn silence (Phaedr. 275d). And if ill-treated or accused of something, they cannot stand up to the challenge themselves but are in utter need of their father to protect them (Phaedr. 275e). Moreover, letters are not able to choose to whom they speak and in front of whom they would rather remain silent (Phaedr. 275e). Letters are not able to make any assessment of the audience. Subsequently, we have to understand that in order to grasp the topic of utmost importance the student has to be able to ask questions and the master has to be able to assess what his student and disciple really needs. ${ }^{38}$

To explain the whole extent of the problem Socrates turns yet to another allegory: A serious farmer never sows the best of his crops in Adonis gardens ${ }^{39}$ that are supposed to serve only as an amusement. He will sow the crop in the best soil and wait patiently for them to grow, even if it takes a much longer time. Exactly in the same manner, Socrates claims, a philosopher would use writing only as a source of amusement

37 Cf. Frentz (2006: 247): "Hypomnesis orients memory to the unreflective recall of writing where no distinction can be made between what is true and what is believed to be true."

38 Yet in another kind of text we find a very similar notion. The Derveni Papyrus, which is a commentary on an Orphic theogony, also stresses the necessity of a living inquiry into the subject in order to be able to grasp the true meaning (Col. XX).

39 Adonis-gardens were gardens sown in shreds or flat vessels with herbs and flowers that die as quickly as they blossom. They symbolized the vegetation god Adonis: the vegetation of spring, which is burnt down by the heat of summer (F. Nötscher (1950), Art. Adonis, RAC I, 95). 
or - in utter necessity - as a treasury of reminders ( $\dot{\varepsilon} \alpha v \tau \tilde{\varphi} \tau \varepsilon \dot{v} \pi \circ \mu \nu \eta \dot{\mu} \mu \alpha \tau \alpha$

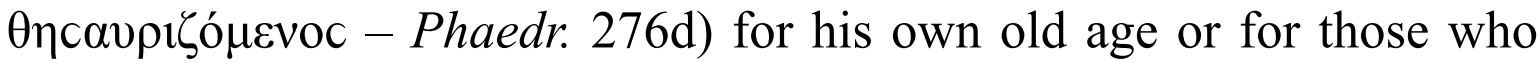
follow the same path. Furthermore, all that is truly valuable and cherished as treasure should not be entrusted to such a fallible and imperfect device.

Interestingly, where Plato is really leading us is the fact that the goal of any wisdom or philosophical knowledge is embraced under the heading of self-knowledge. And in the passage of Phaedrus we see clearly that this self-knowledge does not just emanate from speech, however vivid and flexible it might be. It can be only achieved through establishing relationships between persons: the disciple and the master. And with that we come to the last part where the question of proper wisdom transmission is addressed.

\subsection{Proper Wisdom Transmission}

Phaedrus gives us the first clues as to how to understand proper knowledge transmission. Socrates explains that several conditions have to be met before wisdom can sprout in the soul of the searcher:

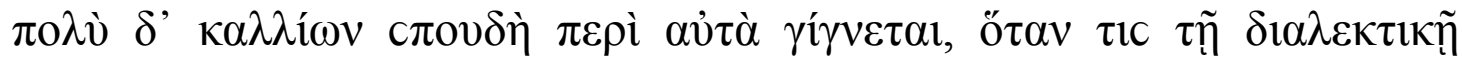

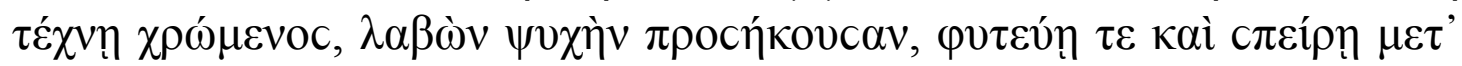

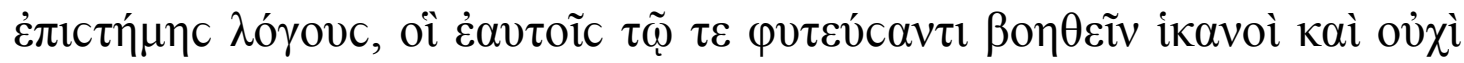

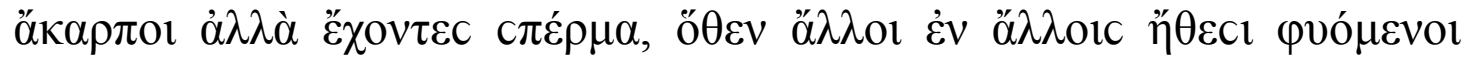

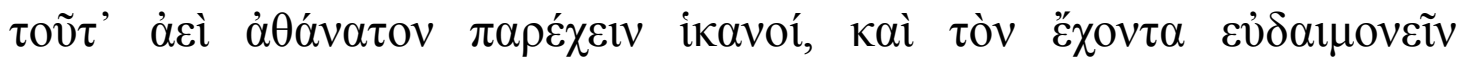

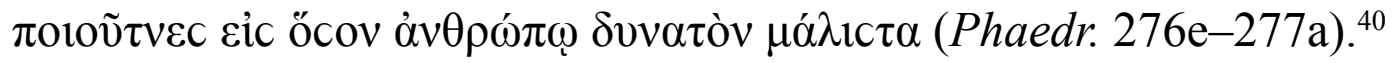

The three conditions are: intelligent words (1) have to be sown using a dialectic method (2) into fitting souls (3). How to understand the term intelligent words can be extracted from the very same passage. An intelligent word is able to help itself (cf. above the helplessness of written word that needs a father for its defence) and is able not only to sprout but even to bear seeds from which the same wisdom can sprout

\footnotetext{
40 'Serious discourse about them is far nobler, when one employs the dialectic method and plants and sows in a fitting soul intelligent words which are able to help themselves and him who planted them, which are not fruitless, but yield seed from which there spring up in other minds other words capable of continuing the process for ever, and which make their possessor happy, to the farthest possible limit of human happiness'.
} 
in other minds. ${ }^{41}$ The most crucial point appears to be the notion of the words making the person who uses them happy to the greatest possible extent. We may ask ourselves what this happiness involves. In the light of previous investigation we can see that the wisdom we are searching for is in fact self-knowledge, knowledge about one's own identity, and happiness is the natural by-product of attaining one's original position. This particular knowledge can be passed down only through the means of dialectics. Apparently, only through the means of living, vivid speech can one transmit the essence of a concept. Therefore, there is no way of conveying this particular message in wiriting. ${ }^{42}$ The last point would be how to define a fitting soul or how to choose those who are worth to be talked to from the position of a philosopher. The Seventh Letter gives us some clues (not exhaustive) on that question. There are two main points in this discourse: the person has to have a proper conduct that does not fuel the desires of the lowest part of the soul (Epist. VII 326c). And then Plato makes the point that when one particular element is missing then not even receptivity or memory will help to attain the right goal. After having discussed memory to such an extent it now appears striking: additionally, the inherent nature of the man has to be fitting and suitable. He has to be truly of one nature with the things being discussed:

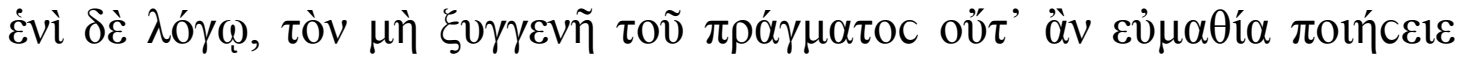

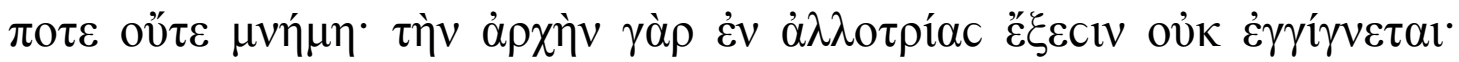

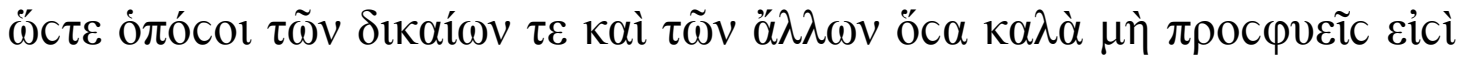

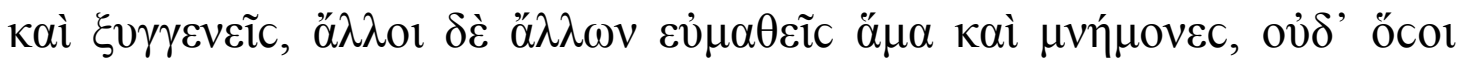

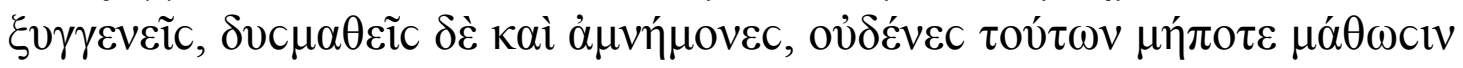

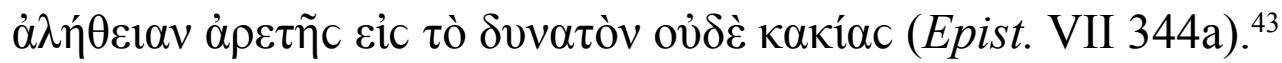

41 The notion of $\lambda$ ó $\gamma o c$ that is able to help itself and all the nuances of this phrase have been investigated lately by Szlezák (1992).

42 In the Seventh Letter Plato brings that point up once again and points out that there is no necessity nor use for putting this message to writing as it is unforgettable and takes up little space. Once that truth is realized, one does not need to entrust it to

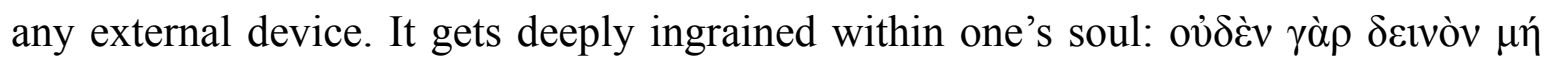

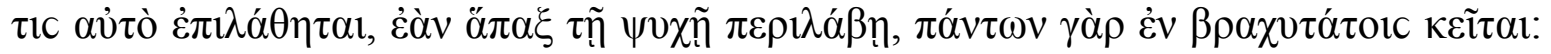
'since there is no fear lest anyone should forget the truth if once he grasps it with his soul, seeing that ut occupies the smallest possible space' $(344 \mathrm{e}$ - here and hereafter transl. Bury).

43 'In one word, neither receptivity nor memory will ever produce knowledge in him who has no affinity with the object, since it does not germinate to start with in alien 
Therefore to enter the realm of real knowledge one has to know in the first place the truth about all that is, about the whole ovicía, about all what there is. Therefore, one has to attain the knowledge - as it seems - of Platonic ideas and see the relation of the external reality to the spiritual, higher reality. Only in that way one attains the condition under which wisdom transmission can happen. This may seem a vicious circle: one has to have it in order to be able to get it. It seems that we have to assume that the prerequisite for attaining this wisdom is at least a theoretical agreement on the preliminary notion of a higher reality. One has to have at least grasped the idea of a spiritual ideal world.

\section{CONCLUSION}

Knowledge about oneself and one's position in the world seems to be what Platonic wisdom really boils down to. ${ }^{44}$ To achieve and transmit it one cannot employ any artificial or external medium, be it poetry or letters. Plato's aim is to liberate man from the bounds of poetry and then not to let him rush into the other trap which seemed so perfect a countersolution to poetry: writing.

He recognized the traps in which the human mind tends to move in order to achieve its own goals and aims - to preserve culture and perpetuate a long-cherished tradition etc. Plato, on the other hand, advocated the quest for truth that he defined as reality beyond appearances. At one, earthly, level the opposite of oral culture appears to be simply the literate one. But Plato does not refer to this one level only. He reaches beyond into a kind of spiritual transcendence looking for true reality. The space he operates in is confined between the $\delta$ ó $\xi \alpha$ and the $\dot{\alpha} \lambda \hat{\eta} \theta \varepsilon 1 \alpha$. Both letters and poetry, as we have seen, being only external devices of memory, enhance the former. Plato seeks only the latter.

states of mind; consequently neither those who have no natural connexion or affinity with things just, and all else that is fair, although they are both receptive and retentive in various ways of other things, nor yet those who posses such affinity but are unreceptive and unretentive - none, I say, of these will ever learn to the utmost possible extent the truth of virtue nor yet of vice'.

44 In the context of the Phaedrus the topic of self-knowledge has been extensively investigated by Griswold $(1981 ; 1996)$. 
And that can be attained only through the means of establishing real relationships. Socrates in Phaedrus (255d) claims that the lover is to the beloved "like a mirror in which the latter beholds himself." 45 To attain self-knowledge one has to find the proper mirror to reflect oneself in. Ultimately the quest for self-knowledge and therefore as well for $\alpha$ vó $\mu v \eta c i c$ has to be a joint venture. ${ }^{46}$ To achieve the real knowledge we have to converse with someone who has it: it gets only transmitted within a personal relationship that can fuel the real philosophical memory.

Apparently, we are persons who have to enter meaningful relationships in order to find out who we really are.

\author{
Abbreviations: \\ PEG Bernabé A., 1996-2007, Poetae Epici Graeci I-II, München-Leipzig. \\ SGO Merkelbach R., Stauber J., 1998-2004, Steinepigramme aus dem griechi- \\ schen Osten $I-V$, Leipzig. \\ RAC Reallexikon für Antike und Christentum, 1950ff, Stuttgart. \\ VS Diels H., Kranz W., 1951-1952, Die Fragmente der Vorsokratiker I-III.
}

\title{
BIBLIOGRAPHY
}

Bury R. G., 1922, Plato VII, London.

Cornford F. M., 1957, From Religion to Philosophy. A Study on the Origins of Western Speculation, London.

Derrida J., 1981, Dissemination, transl. B. Johnson, London.

\footnotetext{
$45 \quad$ Cf. Griswold 1981: 490.

46 This we see as well in the every example of Socrates himself. Just in the beginning of the dialogue he admits that he is not at all interested in questions of the universe as long as he has not fulfilled the mission given him by his presiding deity - Apollo: to know himself. And he definitely considers this to be of utmost priority (Phaedr. 229e5-230a6). Cf. as well Socrates recalling his rejection of Anaxagoras due to the fact that the inquiry into the duties and roles of human beings appear to him far more crucial than the investigation into Nature (Phaed. 97b-98b). Socrates embarks constantly on this quest through the means of involving himself with others (cf. Griswold 1981: 490).
} 
Firth F. M., 1904, The Golden Verses of Pythagoras and Other Pythagorean Fragments, Krotona-Hollywood.

Fowler H. N., 1926, Plato I, London.

Frentz Th., 2006, 'Memory, Myth, and Rhetoric in Plato's "Phaedrus", Rhetoric Society Quaterly 36/3, pp. 243-262, [online:] http://dx.doi. org/10.1080/02773940500511546.

Griswold Ch., 1981, 'Self-Knowledge and the <i $\delta \dot{\varepsilon} \alpha>$ of the Soul in Plato's Phaedrus', Revue de Métaphysique et de Morale 86/4, pp. 477-494.

Griswold Ch., 1996, Self-Knowledge in Plato's Phaedrus, Philadelphia.

Griswold Ch., 2014, 'Plato on Rhetoric and Poetry', [in:] The Stanford Encyclopedia of Philosophy.

Havelock E., 1963, Preface to Plato, London-Cambridge, MA.

Heinrichs A., 2003, '<Hieroi Logoi> and <Hieroi Bibloi>: The (Un)Written Margins of the Sacred in Ancient Greece', Harvard Studies in Classical Philology 101, pp. 207-266.

Notopoulos J., 1938, 'Mnemosyne in Oral Literature', Transactions and Proceedings of the American Phil. Association 69, pp. 465-493.

Obryk M., 2012, Unsterblichkeitsglaube in den griechischen Versinschriften, Berlin-Boston.

Parry M., 1971, The Making of Homeric Verse, Oxford.

Robb K., 1994, Literacy and Paideia in Ancient Greece, New York - Oxford.

Szlezák Th., 1992, 'Was heißt <Dem Logos zu Hilfe kommen>? Zur Struktur und Zielsetzung der platonischen Dialoge', [in:] Understanding the Phaedrus, Proceedings of the II Symposium Platonicum, L. Rossetti (ed.), Sankt Augustin, pp. 93-107.

Thissen H. J., 2002, ‘Ägyptologische Randbemerkungen', Rheinisches Museum 145, pp. 46-61.

Vernant J.-P., 2006, Myth and Thought among the Greeks, transl. J. Ford, J. Lloyd, New York.

Wöhrle G., 1993, 'War Parmenides ein schlechter Dichter?', [in:] W. Kullmann, J. Althoff, Vermittlung und Tradierung von Wissen in der griechischen Kultur, Tübingen, pp. 167-180.

Zalta E. N. (ed.), [online:] <http://plato.stanford.edu/archives/fall2014/entries/ plato-rhetoric/>. 